\title{
ADHESION ASSESSMENT OF COPPER THIN FILMS
}

M.D. KRIESE*, N.R. MOODY** AND W.W. GERBERICH*

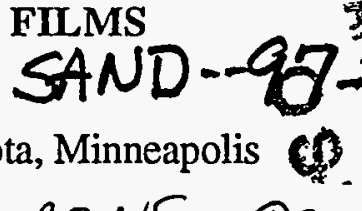
善 6972

*Dept of Chemical Engineering \& Materials Science, University of Minnesota, Minneapolis

**Sandia National Laboratories, Livermore, CA

ABSTRACT

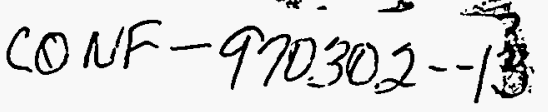

Nano-indentation testing has been used to quantitatively assess the adhesion of thin copper films, sputtered to thicknesses of $150 \mathrm{~nm}$ to $1500 \mathrm{~nm}$. Copper films of low residual stress were deposited via $\mathrm{RF}$ diode cathode sputtering onto $\mathrm{SiO}_{2} / \mathrm{Si}$ substrates. Overlayers of DC magnetron sputtered tungsten, $850 \mathrm{~nm}$ thick with high residual stress, were additionally used to provide a driving force for delamination. All films tested exhibited buckle-driven delamination, from which the interfacial toughness was estimated to be $0.2-2 \mathrm{~J} / \mathrm{m}^{2}$, which is comparable to the thermodynamic work of adhesion. The use of an overlayer requires extensions of existing models, but otherwise does not change the interfacial adhesion, allowing measurements of films that would not otherwise delaminate.

\section{INTRODUCTION}

The adhesion of a thin film is as critical to its performance as any other factor, as film delamination or spallation critically degrades its functionality. There are a great number of semiquantitative tests of film adhesion, such as the peel test, that are reasonably simple to perform. While these tests may be repeatable indicators of relative adhesion, the lack of an absolute value limits their utility for comparisons between film systems, and for use in thermomechanical models and for.correlation with microstructural processes. Truly quantitative analyses have been developed utilizing fracture mechanics concepts, in which delaminations are modeled as bimaterial cracks and film adhesion is characterized by the strain energy released per unit increase in delamination area.1-12 These concepts have been successfully applied to practical test methods. One of the simplest to conduct is the nanoindentation test, ${ }^{13-14}$ in which the indenter initiates an interface crack, and the residual stress along with indentation stress provide the means of driving the crack.

One of the primary difficulties with most quantitative adhesion tests is the introduction of a stable interface crack that is sufficiently larger than the plastic zone around the indenter contact. This geometry allows the delaminated film to be modeled as a clamped circular plate with an interface crack-tip sufficiently removed from the plastic zone to be analyzed with bimaterial fracture mechanics formulations. Particular difficulties are seen with both strongly adhered and ductile films, 3,15 as the film tends to deform rather than delaminate. One method used to promote delamination is the use of a brittle overlayer deposited with high residual stress, such that the reduction of this residual strain energy drives delamination. 15-17

For the experiments described herein, low-stress sputter-deposited thin films of copper in the thickness range of $150 \mathrm{~nm}$ to $1500 \mathrm{~nm}$ are assessed both with, and without, an overlayer of highstress sputter-deposited $855 \mathrm{~nm}$-thick tungsten film. Copper was chosen for several reasons. Copper is easily processed and is a candidate metal for the replacement of aluminum in interconnects of integrated circuits. Additionally, it has a fairly high as-deposited hardness that can be significantly reduced by annealing. These features allow the copper to act as a model "ductile" film in any future assessment of the impact of ductility on adhesion and adhesion testing. Copper films without overlayers are assessed directly to determine the effects of thickness and substrate, and to a lesser extent sputtering conditions. Copper films with overlayers are tested to determine the applicability of the nanoindentation test mechanics, which explicitly treats only delamination of a single film. It is expected that the interfacial adhesion should not be strongly affected by the presence of the tungsten overlayer, and agreement between analysis methods would validate the use of overlayers to assist assessment of a wider range of processing variations. This would then further enable analyses of the relationships between processing, film microstructure and adhesion. 


\section{DISCLAIMER}

This report was prepared as an account of work sponsored by an agency of the United States Government. Neither the United States Government nor any agency thereof, nor any of their employees, make any warranty, express or implied, or assumes any legal liability or responsibility for the accuracy, completeness, or usefulness of any information, apparatus, product, or process disclosed, or represents that its use would not infringe privately owned rights. Reference herein to any specific commercial product, process, or service by trade name, trademark, manufacturer, or otherwise does not necessarily constitute or imply its endorsement, recommendation, or favoring by the United States Government or any agency thereof. The views and opinions of authors expressed herein do not necessarily state or reflect those of the United States Government or any agency thereof. 


\section{DISCLAMMER}

Portions of this document may be illegible in electronic image products. Images are produced from the best available original document. 


\section{EXPERIMENT}

\section{$\underline{\text { Sample Preparation }}$}

Films were deposited onto 4 -in diameter $<100>$ single-crystal silicon wafers oxidized in steam at $1000^{\circ} \mathrm{C}$ for $15 \mathrm{hr}$, resulting in growth of $1650 \mathrm{~nm}$ of $\mathrm{SiO}_{2}$. Profilometer line-scans showed the substrates to have surface roughnesses of $1.0-2.0 \mathrm{~nm}-\mathrm{rms}$, matching that of the predeposition silicon surface. Wafers were processed in a class-10 cleanroom prior to film deposition.

Copper films were deposited with a Perkin Elmer 2400 RF diode cathode using a high-purity 8 " target and argon gas. Nominal deposition rates were nominally $540 \mathrm{~nm} / \mathrm{sec}$ at 1000 watts and $270 \mathrm{~nm} / \mathrm{sec}$ at 500 watts. All films of a given thickness, power and gas pressure were deposited simultaneously by rotating the platen at $1.7 \mathrm{rpm}$. Pumpdown pressure was $1 \times 10^{-6}$ Torr in all cases, and no sputter-etching was performed prior to deposition. Film thickness was measured by profilometry of etched $50 \mu \mathrm{m}$ lines. Post-deposition surface roughnesses matched that of the substrate. The grain size for all films was nominally $50-80 \mathrm{~nm}$ as measured with atomic force microscopy. The thicknesses and sputtering conditions are summarized in Table-I, along with resistivity and average residual stress levels which were measured by wafer curvature changes ${ }^{18-19}$ before and after processing.

Tungsten films were deposited with a Perkin Elmer 2400 DC magnetron using a high-purity 8-in target and argon gas. All samples were deposited simultaneously via platen rotation of 3.3 rpm. Pumpdown pressure was $4.5 \times 10^{-7}$ Torr prior to sputtering at a power of 1000 watts and argon pressure of 10 mTorr. Deposition time was 50 min to a thickness of $850-860 \mathrm{~nm}\left(\mathrm{Si} / \mathrm{SiO}_{2}\right)$ which was measured by profilometry of etched $50 \mu \mathrm{m}$ lines. Changes in wafer curvature showed residual stress levels that varied significantly from wafer to wafer as indicated in Table-I; the source of this variation is unknown.

In all cases, the polycrystalline metal films are assumed to have isotropic elastic constants, matching published values ${ }^{20}$ of $\mathrm{E}_{\mathrm{Cu}}=129.8 \mathrm{GPa}, \mathrm{v}_{\mathrm{Cu}}=0.343, \mathrm{E}_{\mathrm{W}}=411.0 \mathrm{GPa}$ and $\mathrm{v}_{\mathrm{W}}=0.28$. Efforts are in-progress to measure indentation moduli to account for film texture. However, tungsten is isotropic and fcc copper would most likely have a $<111>$ texture, resulting in an indentation modulus only $3 \%$ higher than the isotropic case. 33

\section{Test Procedures}

Pieces of wafers, approximately $1 \mathrm{~cm}$ square, were glued to aluminum mounts, and indented with a $90^{\circ}$ (included angle) conical diamond indenter with an approximately $1 \mu \mathrm{m}$ tip radius. Indentations were performed on a commercially available device, the NanoIndenter II, which has practical resolutions of less than $1 \mu \mathrm{N}$ and $1 \mathrm{~nm}$ respectively. The films were indented under load control at a rate of $600 \mu \mathrm{N} / \mathrm{sec}$, held at maximum load for 30 seconds and unloaded at $600 \mu \mathrm{N} / \mathrm{sec}$. Maximum loads were $10 \mathrm{mN}$ to $950 \mathrm{mN}$. Indentations were examined with an optical microscope to measure delamination area using Nomarski interference contrast to accentuate height differences for accurate determination. Indentation volumes were calculated from estimates of the plastic indentation depth and the shape of the indenter tip.

Table-I. Sample Characteristics. Wafer stress is based on curvature measured with an 8-position capacitance probe. Note: a positive value of stress indicates compression.

\begin{tabular}{|ccccccc|}
\hline Sample & $\begin{array}{c}\text { Power } \\
\text { (watt) }\end{array}$ & $\begin{array}{c}\text { Ar Pressure } \\
\text { (mTorr) }\end{array}$ & $\begin{array}{c}\text { Copper } \\
\text { Thickness } \\
\text { (nm) }\end{array}$ & $\begin{array}{c}\text { Resistivity } \\
(\Omega / \text { square) }\end{array}$ & $\begin{array}{c}\text { Residual } \\
\text { Stress } \\
(\mathrm{MPa})\end{array}$ & $\begin{array}{c}\text { Tungsten Overlayer } \\
\text { Residual Stress } \\
(\mathrm{MPa})\end{array}$ \\
\hline A & 1000 & 10 & 1530 & 0.0014 & 95 & 890 \\
B & 1000 & 10 & 920 & 0.03 & 160 & 570 \\
C & 1000 & 10 & 430 & 0.15 & 35 & 420 \\
D & 1000 & 10 & 150 & 0.23 & 130 & 550 \\
E & 1000 & 20 & 1450 & 0.017 & 125 & 360 \\
F & 500 & 10 & 890 & 0.06 & 30 & 690 \\
G & 500 & 10 & 405 & 0.11 & 130 & 740 \\
\hline
\end{tabular}


A series of tests at load rates of $50 \mu \mathrm{N} / \mathrm{sec}$ and $1200 \mu \mathrm{N} / \mathrm{sec}$ established that load-displacement curves and fractographic features were not sensitive to loading rate. Also, a series of indents to loads ranging 0.8 to $10 \mathrm{mN}$ conducted at $30 \mu \mathrm{N} / \mathrm{sec}$ were used to assess the hardness and indentation modulus of both copper and tungsten films for samples $C$ and D. These tests used a Berkovich tip of approximately $300 \mathrm{~nm}$ tip radius, for which an experimental area-depth calibration is known. Indentation data was analyzed according to the methodology of Oliver and Pharr. ${ }^{21}$

\section{Calculation of Strain Energy Release Rates}

The methodology of Marshall and Evans ${ }^{13}$ was used to characterize the interfacial driving force for delamination, using the solutions by Hutchinson and Suo ${ }^{14}$ for the buckling stress of an axisymmetric clamped plate. The strain energy in a delaminated film is calculated for each of a series of imaginary steps, in which the section of film above a prospective circular interfacial crack is removed, allowed to relax its residual stresses, indented causing radial expansion and recompressed by appropriate stresses required to fit the film back onto the substrate, possibly buckling in so doing. Indentation stress is given by

$$
\sigma_{i}=\frac{E_{f}}{1-v_{f}} \frac{V_{i}}{2 \pi h a^{2}}
$$

where $V_{i}$ is the indentation volume, $h$ is the film thickness, $a$ is the radius of the circular delamination and the subscript ' $f$ ' refers to the elastic constants of the film. If the sum of the indentation stress and the residual stress $\sigma_{R}$ exceeds the critical buckling stress for delamination,

$$
\sigma_{B}=\frac{\mu^{2} E_{f}}{12\left(1-v_{f}^{2}\right)} \frac{h^{2}}{a^{2}}
$$

the film buckles. In the expression, $\mu=\pi$ for simple beams of length $2 \mathrm{a}$ (the one-dimensional approximation) and $\mu^{2}=14.68$ if the buckle occurs over the entire diameter of a clamped circular plate of radius a, referred to as single-buckling. Double-buckling can occur when the indenter pins the center down, causing buckling to be annular, for which $\mu^{2}=42.67$. Buckling releases strain energy, as the stress for a given edge displacement, $\Delta$, after buckling is less than it would be had no buckling occurred. In the absence of an indentation stress, residual stresses can drive delamination only by buckling. The net expression for the strain energy release rate is

$$
G=\frac{h\left(1-v_{f}\right)}{E_{f}}\left[\sigma_{R}^{2}(1-\alpha)+\sigma_{i}^{2}\left\{\frac{1+v_{v}}{2}-(1-\alpha)\left[1-\frac{\sigma_{B}}{\sigma_{i}}\right]^{2}\right\}\right]
$$

where slope of $\sigma / \sigma_{\mathrm{B}}$ vs. $\Delta / \Delta_{\mathrm{B}}$ is $\alpha=1$ before buckling, and after onset of buckling decreases to

$$
\alpha=1-\left[1 /\left(1+0.9201 v_{\mathrm{f}}\right)\right]
$$

For large crack radii, the strain energy release rate asymptotically approaches approximately $75 \%$ of the initial stored elastic energy per unit thickness of the unbuckled film due to the asdeposited residual stresses. ${ }^{14}$ This asymptotic value is

$$
G_{0}=0.75\left[\sigma_{R}^{2} h\left(1-v_{f}\right) / E_{f}\right]
$$

This approach has been used ${ }^{13,22-25}$ to give reasonable results, especially when the residual stress is much larger than the indentation stress, despite such often-encountered difficulties as non- 
circular delamination, radial cracking of the film and the imprecision in measuring the volume displaced by the indenter tip. It is possible to establish bounds between when spallation has occurred and when there is no stable crack after test completion. However, the analysis does assume a single homogeneous film, and is not directly applicable for films with overlayers, unless one film thickness is negligible with respect to the other. In the case of an overlayer of comparable thickness, ignoring the lower layer underestimates both the buckling stress and elastic strain energy stored from the residual stresses. If both layers are accounted for, the appropriate values of $E_{f}, v_{f}$ and $\sigma_{R}$ for use in equations (1) through (4) are no longer clear, especially if the residual stress levels are also different in the two layers.

The approach used herein to utilize the above model for bilayer films used in this study has two parts. First, the critical buckling stress for a bilayer film is determined by calculating a transformed moment of inertia using standard theory of beams in pure bending. ${ }^{26}$ The result is that two films of differing modulus will have a greater moment than a single film of the same total thickness of the lower modulus. This is depicted in Figure 1. The plate is thus treated as if it were of a single material of the transformed moment, and the standard solutions for buckling stress and strain can be used by multiplying by the ratio of transformed to standard moment, as buckling is linearly dependent on the moment of inertia. Using this corrected value of buckling stress, and otherwise ignoring the copper film in equations (1), (3) and (4), yields an initial estimate of the strain energy release rate.

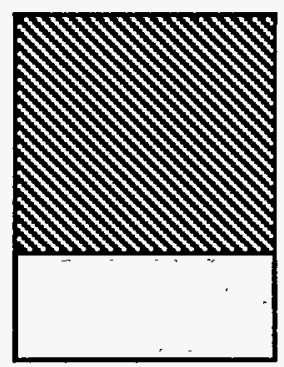

(a)

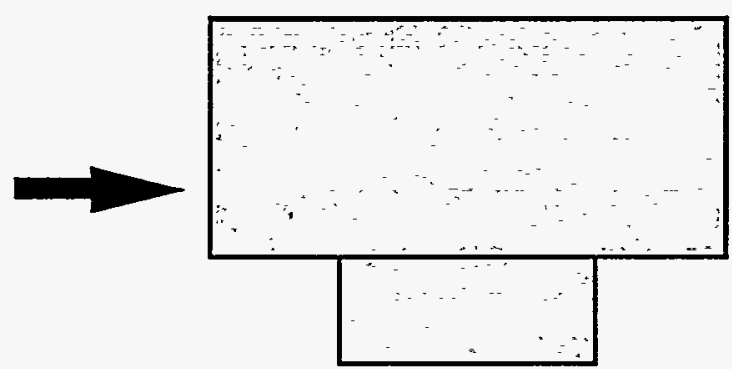

(b)

Figure 1. Transformed Moment of Inertia. A unit width of the composite cross-section of the bilayer shown on the left, in which the overlayer has a higher biaxial modulus $E /\left(1-v^{2}\right)$. The equivalent 'transformed' unit-width cross-section is composed solely of material with elastic constants equivalent to the lower material, but where the 'unit-width' of the upper portion is increased by the ratio of the biaxial elastic moduli.

The second part attempts to account for the difference in elastic constants, thickness and residual stress of each layer, and how they contribute to the strain energy of system after each of the above-mentioned imaginary steps. For this, the bilayer is analyzed with standard composites laminate theory. 27 This analysis allows the computation of an equivalent stiffness matrix to relate the geometric midplane strains and curvatures to applied forces and moments; the geometric midplane deformation is used to calculate the stress and strain distribution within each layer. This is shown schematically in Figure 2. An applied laminate midplane strain and curvature is applied to induce an initial state in the composite laminate in which each layer has an average stress matching the measured average residual stress. Next the additional laminate stress required to produce a laminate midplane strain equal the indentation strain from equation (1b) is calculated. Buckling is assumed to occur when the laminate's change in midplane strain reaches the critical value calculated using the transformed moment; it is further assumed that the value of $\alpha$ is still dictated by equation (4), using a weighted average of the Poisson's ratios. Thus, the strain energy existing in the bilayer laminate for each step can be calculated utilizing the equations in Marshall and Evans ${ }^{13}$. The strain energy release rate is calculated numerically according to

$$
\mathrm{G} \equiv-\frac{1}{2 \pi \mathrm{a}} \frac{\partial \mathrm{U}(\mathrm{a})}{\partial \mathrm{a}}=-\frac{1}{2 \pi \mathrm{a}} \frac{\mathrm{U}(\mathrm{a}+\delta)-\mathrm{U}(\mathrm{a}-\delta)}{2 \delta} \text { for } \delta \ll \mathrm{a}
$$




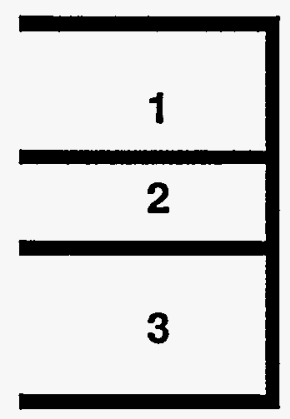

laminate

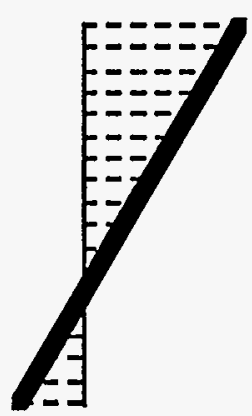

strain

variation

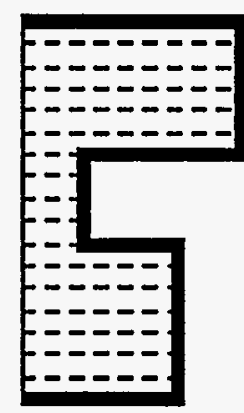

lamina

modulus

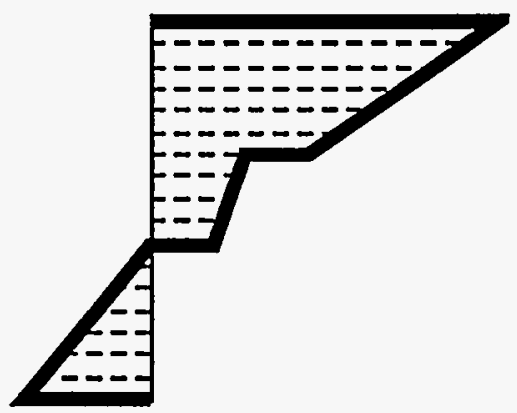

stress variation

Figure 2 Laminate Analysis. When lamina are combined, the laminate's response to loads, moments and temperature changes is a linear variation of strain, $\varepsilon=\varepsilon^{\circ}+\mathrm{zk}$, where $\varepsilon^{\circ}$ and $\mathrm{k}$ are the strain and curvature of the laminate's geometric midplane, and $\mathrm{z}$ is the distance from this midplane. Stress discontinuities are due to variation in lamina moduli; nevertheless, stress is also linear with distance in a given layer.

\section{RESULTS}

Both the copper-only and the copper/tungsten bilayer films of all thicknesses delaminated via indentation testing, producing stable blisters of buckled film. However, the total indentation depth, including the recoverable elastic compression of the film/substrate system, was typically greater than the film thickness. Thus, the blister of film had a large "hole" within its center which consisted of a centered impression of the indenter tip surrounded by a spallation two to five times the diameter of the indent impression. The blisters were thus geometrically similar to volcanoes, with a rim raised $2.0-3.5 \mu \mathrm{m}$ above the top of the surrounding film, and a central depression $1-2$ $\mu \mathrm{m}$ below the top of the surrounding film.

Indentation load-displacement curves typically contained clear indications of the initiation and/or propagation of interface delamination, in the way of significant slope-changes or excursions. Two sets of typical data are shown in Figure 3. When nonlinear deformation other than plasticity occurs, particularly delamination initiation and propagation, there is no clear way to determine what portion of the total indentation depth is due solely to plastic impression of the indenter, i.e. the indentation volume. Similarly, given that film spallation directly around the impression occurs, one cannot measure it afterward. For these experiments, the onset of significant changes in loading, assumed to be associated with the initial stages of crack propagation, is used as a lower bound for plastic depth. Similarly, the depth at which this behavior ceases, often the total depth, is used as an upper bound.

Both the deep penetration and the presence of a hole are problematic for calculations of the single-buckling strain energy release rate, since the mechanics are based on a continuous plate, i.e. without a central hole. With single-buckling, the true stress required to induce buckling is less than that calculated due to the presence of the hole. For the double-buckling case, it depends on when the hole is produced relative to when crack propagation occurs.

\section{Copper Films (No Tungsten Overlaver)}

The copper films have a very high hardness of 4-7 GPa for the $430 \mathrm{~nm}$ film and 8-9 GPa for the $150 \mathrm{~nm}$ film at plastic indentation depths of $10-50 \%$ of film thickness. The scatter is largely independent of maximum load and greater for the thinner film. Yield strength is generally estimated to be one-third the hardness, indicating that these films are capable of supporting very high stresses, which is not surprising given the fine grain size. 

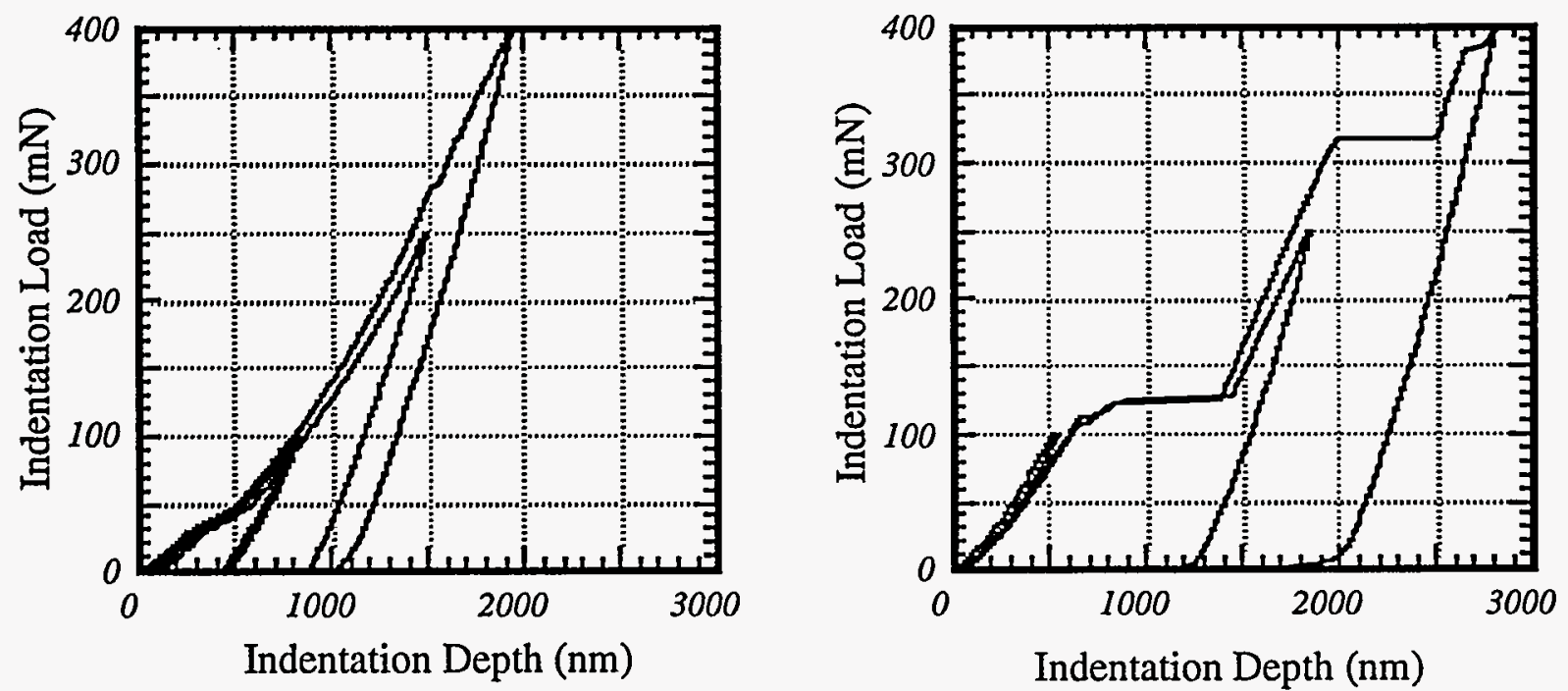

Figure 3. Characteristic Indentation Data. Each sample is loaded to 100,250 and $400 \mathrm{mN}$. The copper-only film (left) of sample $C$ has deviations in loading behavior, which represent delamination and a change in deformation constraint. With the companion copper/tungsten bilayer (right) has abrupt transitions. As the instrument is a load controlled device, a sudden depth increase occurs as the load data remains constant, even if the excursion transition actually involves momentary load drops.

In terms of fractography, low loads merely exhibit an impression surrounded by upheaval, medium loads exhibit single buckles and high loads exhibit ring-structures suggestive of double buckles. Low versus high loads depend on film thickness, such that $100 \mathrm{mN}$ produces impressions in $150 \mathrm{~nm}$ films, but produces single buckles in the thicker films. Similarly, $400 \mathrm{mN}$ loads only produce double buckles in films greater than $900 \mu \mathrm{m}$ thickness. All films exhibited single buckles for at least one of the three loads. Shown in Figure 4 are the indents from sample $\mathrm{B}$, which show the two types of buckles. The plastic zone surrounding an indent is typically 2-3 times the contact diameter ${ }^{28}$ which is significantly smaller than the observed buckles, indicating that buckle-driven delamination occurred, as opposed to pileup around the impression.

However, only for about half the tests do the models predict the observed buckling, as shown in Table II, even when the entire indentation depth is used as the upper bound of indentation volume. This limitation is exhibited primarily for the thicker films. For the thinner films, while there is considerable scatter, most calculations lie in the range of $0.3-1.5 \mathrm{~J} / \mathrm{m}^{2}$.

\section{Copper/Tungsten Bilayers}

The hardness of the tungsten overlayers is $8-10 \mathrm{GPa}$, which additionally behaves in a much more brittle fashion. The dominant feature of delamination is the presence of radial cracks emanating from the central impression, which is really a cracking of the film under the indenter. A typical set of results is shown in Figure 5. Additionally, since the overlayer is stiffer and possesses higher residual stresses, the extent of buckling is up to 10 times larger than without an overlayer. Single buckling is the only observed mode, and occurred with loads as little as $0.5 \mathrm{mN}$ for some samples. The test results are summarized in Table II. It is also worth noting that the indentation load-depth data typically exhibited repeatable load excursions, associated with the initiation and propagation of the delamination. 


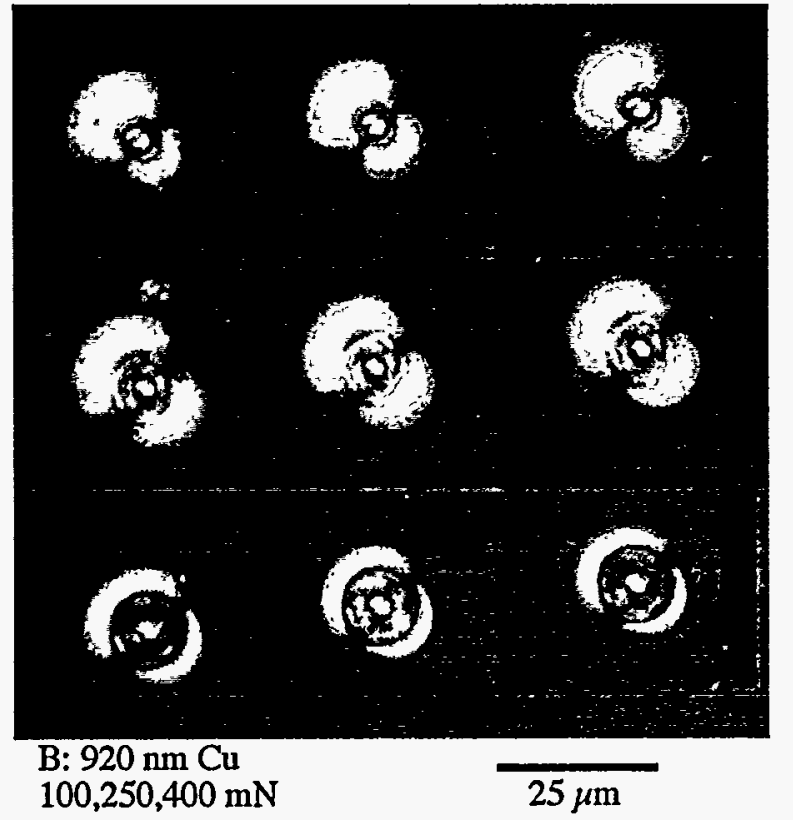

(a)

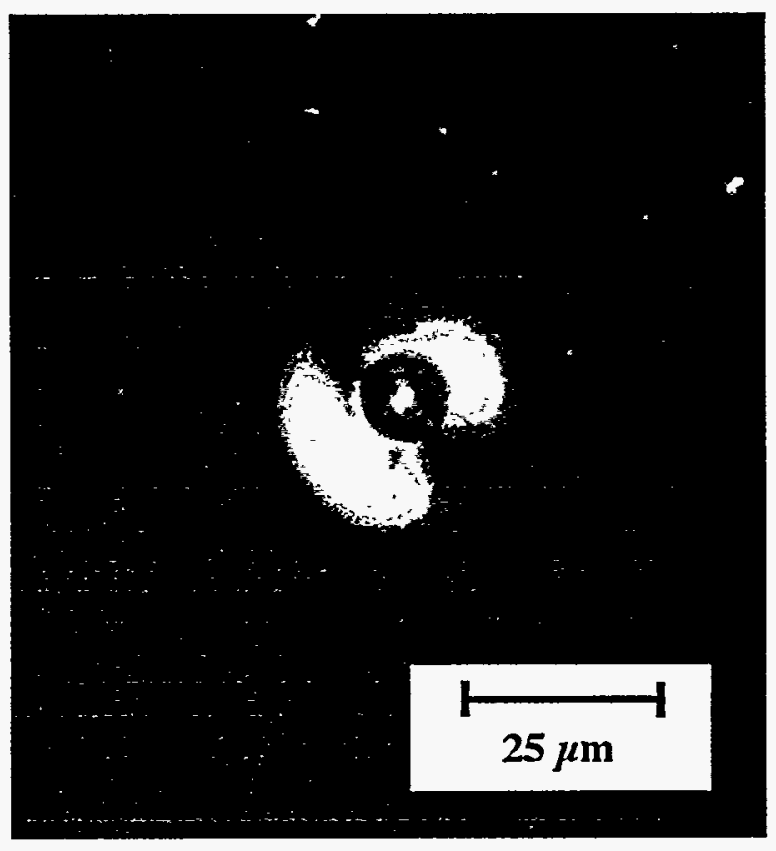

(b)

Figure 4. Characteristic Fractography of Copper Films. (a) 9 tests on sample B (they have been digitally "moved" for presentation, and were actually $100 \mu \mathrm{m}$ apart). The $100 \mathrm{mN}$ and $250 \mathrm{mN}$ tests are at the top and middle, and exhibit single buckling, shown magnified in (b). At $400 \mathrm{mN}$ double buckling is exhibited. The central ring, typically $1 / 4$ to $1 / 3$ the overall buckle diameter, is two to four times the contact diameter. The indenter impression is the smallest bright circle at the center.

Processing of the wafers to etch lines as well as wafer-cracking often induced edge-initiated delamination of the films, either in strips or as a single piece. From these delaminations it was very clear that delamination occurs at the $\mathrm{Cu}-\mathrm{SiO}_{2}$ interface.

Additional features observed on sample $\mathrm{G}$ were the blisters shown in Figure 5b, which buckled spontaneously without indentation. For these blisters, there are no film cracks and no ambiguity in the magnitude of the indentation stress, as it is zero. The observed delamination radii range from $10-100 \mu \mathrm{m}$. For a value of $70 \mu \mathrm{m}$, the critical buckling stress using the transformed moment is $105 \mathrm{MPa}$, a value exceeded by the residual stress of both the copper and the tungsten. Given the higher stress, modulus and thickness of the tungsten overlayer, it is reasonable to assume that the strain energy release rate for these blisters is equal to the sum of the $G_{0}$ values of each film. Using the residual stress levels indicated in Table $I$, this results in a critical delamination value of $0.64 \mathrm{~J} / \mathrm{m}^{2}$.

By using the bilayer calculations of buckling stress, only the larger crack radii of $30 \mu \mathrm{m}$ or more, observed on samples A, C, D and G, are sufficient to predict buckling to occur. The initial estimates use the bilayer buckling stress, but only the tungsten parameters are used to calculate indentation stress and strain energy; this approximation yields a range of $0.2-0.5 \mathrm{~J} / \mathrm{m}^{2}$ for the critical strain energy release rate. These values are comparable to the estimate from the blister. Incorporation of the laminate analysis yields values that range from $0.01-0.4 \mathrm{~J} / \mathrm{m}^{2}$, somewhat lower than the blister estimates discussed above. 


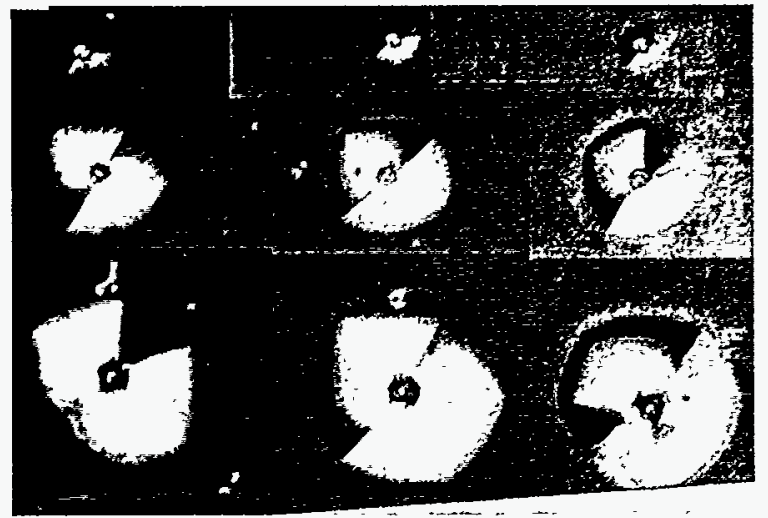

C: $430 \mathrm{~nm} \mathrm{Cu} / 855 \mathrm{~nm} \mathrm{~W}$ [ $100,250,400 \mathrm{mN}$
$100 \mu \mathrm{m}$

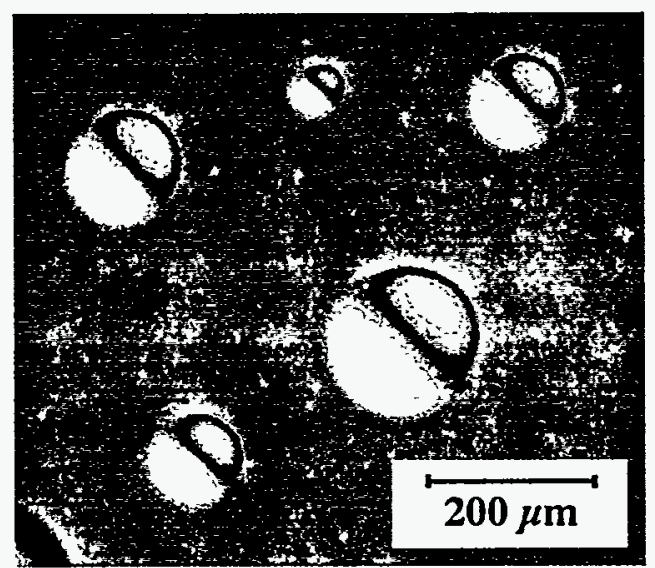

(b)

Figure 5. Characteristic Fractography of $\mathrm{Cu} / \mathrm{W}$ Bilayers. (a) 9 tests on sample $\mathrm{C}$ (they have been digitally "moved" for presentation, and were actually $100 \mu \mathrm{m}$ apart). They are ordered such that $100 \mathrm{mN}$ and $250 \mathrm{mN}$ tests are at the top and middle. (b) Some of the blisters that resulted from specimen preparation, without any indentation. These were perfectly circular, ranging $20-200 \mu \mathrm{m}$ diameter, and are raised by a fraction of a micron of the surface (they are undetectable without Nomarski contrast).

Table II. Indentation-induced Buckling Results. I=impression $\mathrm{S}=$ single-buckle $\mathrm{D}=$ double-buckle All crack lengths averaged to nearest half-micron. Strain energy release rate listed as a range to reflect the range of indentetion volumes; an $\mathrm{X}$ indicates that calculations do not predict the observed buckling.

\begin{tabular}{|c|c|c|c|c|c|c|c|c|}
\hline \multirow[b]{2}{*}{ Sample } & \multicolumn{4}{|c|}{ Copper Films } & \multicolumn{4}{|c|}{ Copper/Tungsten Bilayers } \\
\hline & $\begin{array}{l}\text { Load } \\
(\mathrm{mN})\end{array}$ & Result & $\begin{array}{c}\text { Radius } \\
(\mu \mathrm{m})\end{array}$ & $\underset{\left(\mathrm{J} / \mathrm{m}^{2}\right)}{\mathrm{G}}$ & $\begin{array}{l}\text { Load } \\
(\mathrm{mN})\end{array}$ & Result & $\begin{array}{l}\text { Radius } \\
(\mu \mathrm{m})\end{array}$ & $\begin{array}{c}G \\
\left(\mathrm{~J} / \mathrm{m}^{2}\right)\end{array}$ \\
\hline \multirow{3}{*}{ A } & 100 & $\bar{S}$ & 14.0 & $\mathrm{X}$ & 100 & $\mathbf{S}$ & 21.0 & $\bar{X}$ \\
\hline & .250 & S & 16.0 & $\mathrm{X}$ & 250 & $S$ & 20.0 & $\mathrm{X}$ \\
\hline & 400 & $\underline{S}$ & 16.5 & $\underline{X}$ & 400 & $\underline{S}$ & 40.0 & $0.01-0.15$ \\
\hline \multirow{3}{*}{ B } & 100 & $\mathbf{S}$ & 12.0 & $\mathrm{X}$ & \multirow{3}{*}{\multicolumn{4}{|c|}{ not tested }} \\
\hline & 250 & $S$ & 12.5 & $\mathrm{X}$ & & & & \\
\hline & 400 & D & 10.0 & $\mathrm{X}$ & & & & \\
\hline \multirow{3}{*}{$\mathrm{C}^{\dagger}$} & 100 & $\overline{\mathrm{D}}$ & 7.5 & $X-4.4$ & 100 & $\mathbf{S}$ & 12.0 & $\mathbf{X}$ \\
\hline & 250 & $\mathrm{D}$ & 7.5 & $5-22$ & 250 & $\mathbf{S}$ & 29.5 & $0.01-0.3$ \\
\hline & 400 & $S$ & 15.0 & $0.5-2$ & 400 & $\mathbf{S}$ & 45.0 & $0.2-0.4$ \\
\hline \multirow{3}{*}{$\mathrm{D}$} & 100 & $\mathrm{I}$ & 3.0 & n/a & 100 & $\mathrm{~S}$ & 12.5 & $\mathbf{X}$ \\
\hline & 250 & $S$ & 7.5 & $0.2-1.5$ & 250 & $S$ & 46.0 & $0.1-0.4$ \\
\hline & 400 & S & 15.0 & $0.1-0.4$ & 400 & $S$ & 31.0 & $0.01-0.3$ \\
\hline \multirow{3}{*}{ E } & 100 & $\bar{S}$ & 6.5 & $\bar{X}$ & & & & \\
\hline & 250 & D & 8.0 & $\mathrm{X}$ & 50 & $S$ & 2.5 & $\mathrm{X}$ \\
\hline & 400 & $\mathrm{D}$ & 9.0 & $\mathrm{X}$ & 100 & $S$ & 18.0 & $\mathrm{X}$ \\
\hline \multirow{3}{*}{$\mathrm{F}$} & 100 & $\bar{S}$ & 17.0 & $\bar{X}$ & \multirow{3}{*}{\multicolumn{4}{|c|}{ not tested }} \\
\hline & 250 & $S$ & 19.0 & $\mathrm{X}$ & & & & \\
\hline & 400 & $S$ & 19.5 & $0.4-2.6$ & & & & \\
\hline \multirow{3}{*}{ G } & 100 & $\bar{I}$ & 9.0 & $\mathrm{n} / \mathrm{a}$ & 100 & $\bar{S}$ & 44.0 & $0.2-0.4$ \\
\hline & 250 & I & 9.0 & $\mathbf{n} / \mathbf{a}$ & 250 & $S$ & 72.0 & 0.4 \\
\hline & 400 & $S$ & 16.0 & $0.7-3.0$ & 400 & $\underline{S}$ & 84.0 & 0.4 \\
\hline
\end{tabular}

$\uparrow:$ These are the only samples with double-buckles for which calculations also predict double-buckling. However, for the depths associated with the indentation stress, the buckle is not really point constrained in the center, and these values do not account for such behavior. 


\section{DISCUSSION}

It is clear from both fractography and the indentation load-depth characteristics that buckledriven delamination of the copper and copper/tungsten films occurs in a repeatable manner. The correlation between buckled crack radius and maximum load seems to be independent of film thickness; the minor variations in the data are more likely due to differences in the residual stress from sample to sample. These strongly suggest that delamination resistance is dictated by the interfacial characteristics, as any mechanisms such as plasticity would depend on thickness. Indeed, the calculations of the critical strain energy release rate are somewhat consistent between the test methods and the observed blisters, having a range of $0.1-2 \mathrm{~J} / \mathrm{m}^{2}$. This range is consistent with other measurements of $1-10 \mathrm{~J} / \mathrm{m}^{2}$ using double cantilever beams. ${ }^{29}$ In fact, in systems where roughness related shielding and plastic dissipation are minimal, delamination resistance, i.e. the interfacial toughness, is comparable to the thermodynamic work of adhesion,

$$
\mathrm{W}_{\mathrm{ad}}=\gamma_{\mathrm{Cu}}+\gamma_{\mathrm{SiO} 2}-\gamma_{\mathrm{Cu} / \mathrm{SiO} 2}
$$

where estimates of the first two surface energies made from sessile drop measurements are $1.3 \mathrm{~J} / \mathrm{m}^{2}$ and $4 \mathrm{~J} / \mathrm{m}^{2} .{ }^{30-32}$ In fact, this quantity is often seen to leverage all other contributions to interfacial toughness, ${ }^{4}$ though it should be noted that this quantity is very sensitive to impurity segregants. The values measured for the high yield-strength copper films agree fairly well.

Nonetheless, it is evident that there are serious discrepancies regarding use of the mechanics described to quantify the interfacial toughness in that even for overestimates of the indentation volume, it fails to predict buckling where it is observed. For the case of single buckling, the source of this discrepancy is most likely the hole introduced by the indenter tip. This hole, once the tip is removed, would significantly reduce the stress needed to induce buckling, relative to calculations made assuming a continuous film. For low-stress films such as the copper studied, the introduction of a hole is a necessity, as very high indentation stresses are required to initiate and propagate the crack. While smaller indentation stresses are required with the high-stress tungsten overlayer, this film tends to crack under and away from the indenter tip, also reducing the stresses required for buckling. Furthermore, the single-film mechanics are only valid for very large crack lengths of the bilayer, where the driving force begins to asymptote and the copper film can be safely neglected. This situation also requires higher indentation depths which promote film cracking, but can most likely be avoided by changing thickness, residual stress and/or material of the overlayer.

With regard to the modifications involving laminate analysis, there are some serious deficiencies. In particular is the use of an initial curvature, which was used along with an initial edge load to introduce the measured average stresses in the films as discussed in the Experiment section. The intention was to avoid arbitrary assignment of some $\sigma_{R}$ for use in equation (3) that appropriately accounts for the differences in the two films. However this curvature, equivalent to a fictitious applied moment, in combination with curvatures originating with the bending-stretching coupling of bilayer laminate stiffness matrix, results in a radius of curvature on the order of $1 \mathrm{~mm}$. As a point of reference, radii of curvature measured to evaluate residual stress of the wafers were 10 to 100 meters. Additionally, for large crack radii the asymptotic strain energy release rate underestimates $\mathrm{G}_{0}$ by a factor of two as given by equation (5). Similarly, it in the limit of zero copper thickness, it results in only about half the result given by equation (3). Both of these limitations would suggest that the lower values calculated for the bilayers are underestimates, a conclusion further warranted by comparison to the blister estimates. However, other assumptions are in progress that may correct this.

\section{CONCLUSIONS}

Indentation testing has been conducted on sputtered low-stress copper films of thickness 150 $\mathrm{nm}$ to $1530 \mathrm{~nm}$. Tests on films with and without high-stress $855 \mathrm{~nm}$ tungsten overlayers yielded quantitative assessments of the toughness of $\mathrm{Cu} / \mathrm{SiO}_{2}$ interfaces. Buckle-driven delamination is exhibited, with the higher stress of the tungsten overlayer producing larger delaminations.

Delamination radius correlated with applied load, film thickness, and the films' residual stresses. 
Values for the critical strain energy release rate were calculated to be $0.2-2 \mathrm{~J} / \mathrm{m}^{2}$, which is consistent with the thermodynamic work of adhesion. The interfaces are very smooth, and the films have very high yield strengths due to the small grain size; hence contributions such as roughness shielding and plastic dissipation are unlikely.

There are practical difficulties associated with the technique, in particular, assessment of the indentation stress and quantification of the effects of indentation defects on the buckling stress. However, it has successfully been shown that the use of a high-stress high-stiffness overlayer is a promising technique for assessment of interfacial toughness of films that prove problematic when tested alone. Appropriate extensions of the model to properly account for both films of the bilayer are necessary. Those extensions used in this study have deficiencies, but nonetheless give reasonable values.

\section{ACKNOWLEDGMENTS}

M. Kriese thanks the University of Minnesota Microtechnology Laboratory and in particular Tony Whipple for his tremendous help with sample preparation, as well D. Bahr, D. Kramer and M. deBoer for their valuable assistance. M. Kriese, N.R. Moody and W.W. Gerberich gratefully acknowledge the support of the Center for Interfacial Engineering at the University of Minnesota under grant NSF/CDR-8721551 and the Department of Energy under DOE/DE-FG02/96ER45574.

\section{REFERENCES}

1. J.R. Rice, J. Appl. Mech., 55, 98-103 (1988).

2. H.C. Cao and A.G. Evans, Acta metall., 39, 2997 (1991).

3. A.G. Evans and B.J. Dalgleish, Mater. Sci. \& Eng., A162, 1 (1993).

4. A.G. Evans, M. Rühle, B.J. Dalgleish, and P.G. Charalambides, Mater. Sci. \& Eng., A126, 53-64 (1990).

5. M.D. Thouless, A.G. Evans, M.F. Ashby, and J.W. Hutchinson, Acta metall., 35, 1333 (1987).

6. Z. Suo and J.W. Hutchinson, Int. J. of Frac., 43, 1 (1990).

7. J.W. Hutchinson, M.D. Thouless, and E.G. Liniger, Acta metall., 40, 295 (1992).

8. M.D. Thouless, J.W. Hutchinson, and E.G. Liniger, Acta metall., 40, 2639-2649 (1992).

9. A.G. Evans, M.D. Drory, and M.S. Hu, J. Mater. Res., 3, 1043-1049 (1988).

10. H.M. Jensen, J.W. Hutchinson, and K.-S. Kim, Int. J. Sol. Struc., 26, 1099-1114 (1990).

11. H.M. Jensen and M.D. Thouless, Int. J. Sol. Struc., 30, 779 (1993).

12. H.C. Cao and A.G. Evans, Mechanics of Materials, 7, 295-304 (1989).

13. D.B. Marshall and A.G. Evans, J. Appl. Phys., 56, 2632-2638 (1984).

14. J.W. Hutchinson and Z. Suo, Mixed mode cracking in layered materials, in Advances in Applied Mechanics (Academic Press, Inc., New York, 1992), p. 63-169.

15. A. Bagchi, G.E. Lucas, Z. Suo, and A.G. Evans, J. Mater. Res., 9, 1734 (1994). 
16. N.R. Moody, R.Q. Hwang, J.E. Angelo, S. Venkataraman, and W.W. Gerberich, submitted to Acta Materialia (1997).

17. D.F. Bahr, J.W. Hoehn, N.R. Moody, and W.W. Gerberich, submitted to Acta Materialia (1997).

18. M. Ohring, in The Materials Science of Thin Films, (Academic Press, New York, 1992).

19. G.C. Stoney, Proc. R. Soc. London, A82, 172 (1909).

20. M.A. Meyers and K.K. Chawla, in Mechanical Metallurgy - Principles and Applications (Prentice-Hall Inc., Englewood Cliffs, NJ, 1984).

21. W.C: Oliver and G.M. Pharr, J. Mater. Res., 7, 564 (1992).

22. C. Rossington, A.G. Evans, D.B. Marshall, and B.T. Khuri-Takub, J. Appl. Phys., 56, 2639-2644 (1984).

23. T.F. Page and S.V. Hainsworth, Surfaces and Coatings, 61, 201 (1993).

24. L.G. Rosenfield, J.E. Ritter, T.J. Lardner, and M.R. Lin, J. Appl. Phys., 67, 3291-3296 (1990).

25. J.L. Loubet, J.M. Georges, and P. Kapsa, in Proc. of the 16th Leeds-Lyon Symposium on Tribology, edited by D. Dowson, (Elsevier, Lyon, France, 1990), p. 429.

26. F.P. Beer and E.R. Johnston Jr., in Mechanics of Materials (McGraw-Hill, New York, 1981).

27. B.D. Agarwal and L.J. Broutman, in Analysis and Performance of Fiber Composites (John Wiley \& Sons, Inc., 1990).

28. K.L. Johnson, in Contact Mechanics (Cambridge University Press, New York, 1985).

29. T.S. Oh, J. Rodel, R.M. Cannon, and R.O. Ritchie, Acta metall., 36, 2083 (1988).

30. J.R. Rice and J.S. Wang, Mater. Sci. \& Eng., A107, 23 (1989).

31. D.R. Lide, in 73rd ed., (CRC Press, 1993), p. Pages.

32. B. Lawn, in Fracture of Brittle Solids (Cambridge University Press, 1993).

33. J.W. Hoehn, Ph.D. Thesis, University of Minnesota, 1996. 